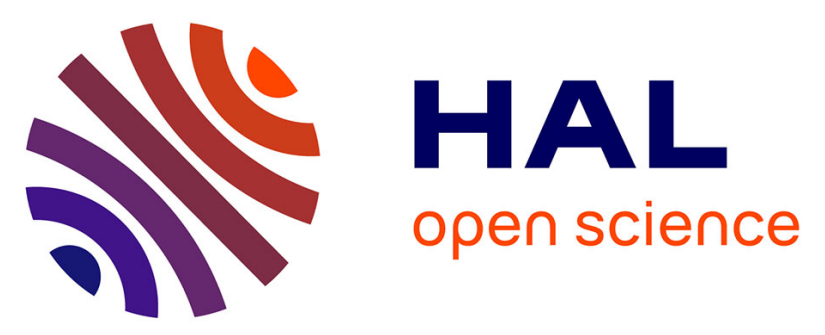

\title{
DIVA, a 3D virtual reality platform, improves undergraduate craniofacial trauma education
}

Jebrane Bouaoud, Mohamed El Beheiry, Eve Jablon, Thomas Schouman, Chloé Bertolus, Arnaud Picard, Jean-Baptiste Masson, Roman Khonsari

\section{- To cite this version:}

Jebrane Bouaoud, Mohamed El Beheiry, Eve Jablon, Thomas Schouman, Chloé Bertolus, et al.. DIVA, a 3D virtual reality platform, improves undergraduate craniofacial trauma education. Journal of Stomatology, Oral and Maxillofacial Surgery, 2020, 10.1016/j.jormas.2020.09.009 • hal-02974248

\author{
HAL Id: hal-02974248 \\ https://hal.science/hal-02974248
}

Submitted on 9 Dec 2020

HAL is a multi-disciplinary open access archive for the deposit and dissemination of scientific research documents, whether they are published or not. The documents may come from teaching and research institutions in France or abroad, or from public or private research centers.
L'archive ouverte pluridisciplinaire $\mathbf{H A L}$, est destinée au dépôt et à la diffusion de documents scientifiques de niveau recherche, publiés ou non, émanant des établissements d'enseignement et de recherche français ou étrangers, des laboratoires publics ou privés. 
1 DIVA, a 3D virtual reality platform, improves undergraduate craniofacial trauma education

2 Short title VR in craniofacial trauma education

3

4 Jebrane Bouaoud, $\mathrm{MD}^{1,2,{ }^{*}}$; Mohamed El Beheiry, $\mathrm{PhD}^{3}$ *; Eve Jablon ${ }^{4}$; Thomas Schouman

$5 \mathrm{MD} \mathrm{PhD}^{2}$; Chloé Bertolus MD $\mathrm{PhD}^{2}$; Arnaud Picard MD $\mathrm{PhD}^{1}$; Jean-Baptiste Masson, $6 \mathrm{PhD}^{3, \dagger}$; Roman H. Khonsari, $\mathrm{MD} \mathrm{PhD}^{1, \dagger}$

24 jebrane.bouaoud@gmail.com

25 Phone\# +33142161049

* contributed equally as first authors

$\uparrow$ contributed equally as last authors

\section{Corresponding author:}

Jebrane Bouaoud, MD

1. Assistance Publique - Hôpitaux de Paris, Service de Chirurgie maxillo-faciale et Chirurgie plastique, Hôpital Universitaire Necker - Enfants Malades; Université Paris Descartes, Université de Paris; Paris, France.

2. Assistance Publique - Hôpitaux de Paris, Service de Chirurgie maxillo-faciale et Stomatologie, Hôpital Universitaire Pitié-Salpêtrière, Université Pierre et Marie Curie, Sorbonne Université; Paris, France

3. Decision and Bayesian Computation, Neuroscience Department UMR 3571 \& USR 3756 (C3BI/DBC), Institut Pasteur \& CNRS, Paris, France

4. Université Paris Descartes, Université de Paris; Paris, France.

Service de Chirurgie maxillo-faciale et Chirurgie plastique, Hôpital Universitaire Necker Enfants Malades, 149 rue de Sèvres, 75015 Paris, France 


\section{Financial Disclosure Statement:}

28 We acknowledge funding from Institut Pasteur, Institut Curie, Paris Sciences Lettres and the 29 sponsorship of CRPCEN, Gilead-Sciences, and fondation EDF, the "programme 30 d'investissement d'avenir" supported by the "agence nationale de la recherche" ANR-1931 P3IA-0001 (PRAIRIE 3IA Institute), INCEPTION project (PIA/ANR- 16-CONV-0005, 32 OG)), and TRamWAy ANR-17-CE23-0016.

\section{Conflict of interest}

35 Mohamed El Beheiry and Jean-Baptiste Masson are cofounders, shareholders and scientific 36 advisors of Avatar Medical.

37 Jean-Baptiste Masson is one of the scientific advisors of the Robeauté startup. 
39 All authors have participated to the conception and design, acquisition of data, or analysis and 40 interpretation of data;

41 All authors have participated to the drafting the article or revising it critically for important 42 intellectual content;

43 All authors have approved the final version to be published;

44 All authors have participated to the agreement to be accountable for all aspects of the work in 45 ensuring that questions related to the accuracy or integrity of any part of the work are 46 appropriately investigated and resolved

48 Approval and confirming statements

49 This study was approved by Institutional review board and performed in accordance with the 50 Helsinki declaration. Collection of data and analysis were in accordance with guidelines of 51 the French National Committee for the Protection of Personal Data (Commission Nationale 52 Informatique et Libertés, CNIL, declaration number 2218907v0). 

4 6 7 8 9 10

\section{Abstract}

Craniofacial fractures management is challenging to teach due to the complex anatomy of the head, even when using three-dimensional CT-scan images. DIVA is a software allowing the straightforward visualization of CT-scans in a user-friendly three-dimensional virtual reality environment. Here, we assess DIVA as an educational tool for craniofacial trauma for undergraduate medical students.

59 Three craniofacial trauma cases (jaw fracture, naso-orbital-ethmoid complex fracture and Le 60 Fort 3 fracture) were submitted to 50 undergraduate medical students, who had to provide 61 diagnoses and treatment plans. Each student then filled an 8-item questionnaire assessing 62 satisfaction, potential benefit, ease of use and tolerance. Additionally, 4 postgraduate students 63 were requested to explore these cases and to place 6 anatomical landmarks on both virtual 64 reality renderings and usual slice-based three-dimensional CT-scan visualizations.

65 High degrees of satisfaction (98\%) without specific tolerance issues (86\%) were reported. The 66 potential benefit in a better understanding of craniofacial trauma using virtual reality was 67 reported by almost all students (98\%). Virtual reality allowed a reliable localization of key 68 anatomical landmarks when compared with standard three-dimensional CT-scan 69 visualization.

70 Virtual reality interfaces such DIVA are beneficial to medical students for a better 71 understanding of craniofacial trauma and allow a reliable rendering of craniofacial anatomy.

\section{Keywords:}

73 virtual reality; data visualization; image processing; craniofacial; traumatology; education 
75 Craniofacial trauma is difficult to teach due to the complex anatomy of the skull [1]. Threedimensional (3D) CT-scans help in visualizing fracture lines based on exploration of the 3D objects on 2D screens. Virtual reality (VR) is a technology that uses real-world visual perception within entirely artificial computer-generated environments. VR allows users to efficiently explore 3D environments in an entirely immersive manner, providing a natural and spatially realistic experience [2].

The benefits of VR in craniofacial surgery have been assessed in previous studies [3]. Almost all studies reported the use of VR for pre-operative planning [4] and intra-operative assistance [5], notably in implantology, orthognathic surgery and maxillofacial reconstruction [3]. Few studies have reported the benefits of VR in surgical education. Within the educational literature, radiology [6] and implantology [7] applications have been evaluated but no study has been dedicated to craniofacial trauma to date.

DIVA (Data Integration and Visualization in Augmented and Virtual Environments, Pasteur Institute, Paris) is a software allowing a fast and user-friendly visualization of raw CT-scan data with immediate immersion [8,9]. DIVA allows users to intuitively navigate in a flexible 3D environment with virtual handheld tools that can be used to interact with 3D images in real-time including landmarking, clipping and highlighting tools.

Here we assess DIVA as an educational tool for teaching craniofacial trauma using a dedicated questionnaire. We furthermore assess the anatomical precision of this tool using anatomical landmark placement. 
1. VR in craniofacial trauma education: benefits and tolerance

Three craniofacial trauma cases (jaw fracture, naso-orbital-ethmoid complex fracture and Le Fort 3 fracture) were submitted to 50 fourth-year undergraduate medical students from the University of Paris, who had to provide a diagnosis and a treatment plan. For each student, pre- and post-operative CT-scans were assessed using both a freeware DICOM viewer (RadiAnt, Medixant, Poznan, Poland) and DIVA (Figure 1).

103 The DIVA interface offers two visualization tools: (1) a desktop tool for standard 3D 104 visualization and (2) the VR environment. The desktop tool was used to reconstruct the skull 105 in 3D based on pre-defined transfer functions. This same visualization is seamlessly switched 106 to the VR viewing context where it can be physically interacted with (Figure 2 and 107 Supplemental Digital Contents 1-3).

108 After using the DICOM viewer and DIVA, each undergraduate medical student filled a 109 questionnaire based on 8 items assessing satisfaction, potential benefit, comfort of use and 110 tolerance.

\section{2. Anatomical precision of VR}

1134 postgraduate students were requested to explore these cases and to place 6 anatomical 114 landmarks on two types of 3D renderings: (1) 3D reconstructions from CT-scan using Avizo 115 (ThermoFisher Scientific, Waltham, MA, USA) and (2) 3D renderings of the same DICOM 116 data using the DIVA VR interface.

117 The landmarks selected were: (1) anterior nasal spine, (2) posterior nasal spine, (3) distal 118 palatal cusp of tooth 17 (right second maxillary molar), (4) distal palatal cusp of tooth 27 (left 119 second maxillary second molar), (5) apex of the crista galli process and (6) apex of the 
120 odontoid process of C2. Landmarks on both rendering were positioned 3 successive times (3 1 121 trials) by the 4 subjects and 3D coordinates were extracted. Geometric morphometrics was 122 performed using MorphoJ (Apache License, Version 2.0) [10]. After screening for outliers 123 and Procrustes superimposition, canonical variate analysis on Procrustes coordinates using 124 both trials and subjects as classifier variables allowed to compute Procrustes distances 125 between groups (trials and subjects) [11]. Permutation test for pairwise distances with 10000 126 iterations allowed obtaining p-values accounting for the significance of Procrustes distances 127 between trials 1-3 and subjects $1-4$.

128 We furthermore evaluated the variability in landmark positioning by assessing inter- and 129 intra-individual error rates, defined as the variance of the position divided by $\mathrm{N}-1$, with $\mathrm{N}$ 130 being the number of points. 
135 (question 1, responses defined as "very satisfied" and "more than satisfied") when using 136 DIVA to explore and analyze craniofacial trauma cases (Table 1). The use of DIVA was 137 deemed easy, intuitive (88\%) and well tolerated (86\%) (questions 2 and 3, Table 1). 138 Furthermore, DIVA allowed students to visualize some lesions not seen on the usual 2D and $1393 \mathrm{D}$ renderings $(82 \%)$, such as skull base and pterygoid process fractures (questions 4 and 5 , 140 Table 1). Almost all students strongly recommended the use of DIVA for educational 141 purposes in traumatology (questions 6-8, Table 1).

\section{Anatomical precision of VR}

Geometric morphometrics analyses showed that all p-values accounting for the significance of Procrustes distances between trials 1-3 and subjects 1-4 were $>0.05$ : landmarking using standard 3D CT-scan visualization and landmarking using DIVA provided a similar 3D display of landmarks, without significant distortion. All mean 3D errors, exploring the variability in landmark positioning, were lower than 1 millimeter, ranging from 0.37 to 0.84 millimeters (Figure 3 and Supplemental Digital Contents 4). 
Discussion

Craniofacial anatomy is challenging to teach to undergraduate medical students and common misunderstandings lead to pitfalls in diagnosis and treating head and neck trauma. While the teaching of traditional anatomy usually involves books and cadaveric dissection, which 155 requires significant amounts of time and effort, other teaching methods can be beneficial [12$15614]$

157 VR has been recently re-introduced in medical schools as an easy-to-access technology due to 158 the availability of low-cost VR headsets. Through the integration of stereoscopy, motion 159 tracking technologies and total 3D immersion, VR aims at providing a more natural means to 160 visualize 3D structures. VR headsets are bundled with 3D controllers (that act as 3D computer 161 mice) allowing manipulation and interaction with data within the virtual environment. 162 Interactions with the VR controller are rather intuitive as they are performed as if the data 163 were physically present in front of the user.

164 DIVA is a software that automatically generates detailed 3D reconstructions of tomographic 165 medical images such as CT-scans. The avatar generated by DIVA based on raw DICOM CT166 scan images is generated through volumetric reconstruction without pretreatment (e.g. 167 segmentation). DIVA is optimized to ensure high refresh rate (at least $60 \mathrm{~Hz}$ ) and a high 168 quality of volume rendering and thus provides a fluid experience. Users are free from latency 169 issues that induce negative experience within VR environments [9].

171 Here we showed that using DIVA to explore and analyze 3D CT-scans[8] improved the 172 understanding craniofacial trauma. Furthermore, we found a high degree of interobserver 173 reproducibility reflecting the precision and accuracy of this tool to explore head and neck 3D 174 anatomy and landmarking. 
175 As outlined by Alsabbagh et al., craniofacial fractures may be better interpreted using VR 176 compare to usual CT-scan renderings[15]. We furthermore found that $82 \%$ of students 517 reported spotting lesions using VR that they had missed on usual 3D renderings, thus confirming that VR is beneficial for exploring complex 3D objects [16].

180 The value of VR in understanding fractures has recently been reported in orthopedics [17] and 181 in pre-surgical planification of maxillofacial cases [18], as well as in dental education [19]. 182 Roessel et al. have recently reported a systematic literature review supporting the using of VR 183 in surgical education and training [20].

185 In brief, VR solutions such as DIVA can complement conventional teaching methods (2D 186 sketches, 3D renderings, cadaveric dissections) when complex 3D structures such as the skull 187 are involved [21-24]. High satisfaction and tolerance degrees could be obtained using VR 188 tools such as DIVA. Beyond traumatology, similar tools may be used to explore craniofacial 189 malformations and head and neck cancers, by combining CT-scan and MRI data. 
[1] Review: Anatomy of Head \& Neck | SEER Training n.d. https://training.seer.cancer.gov/head-neck/anatomy/review.html (accessed February 16, 2020).

[2] El Beheiry M, Doutreligne S, Caporal C, Ostertag C, Dahan M, Masson J-B. Virtual Reality: Beyond Visualization. J Mol Biol 2019;431:1315-21. https://doi.org/10.1016/j.jmb.2019.01.033.

[3] Ayoub A, Pulijala Y. The application of virtual reality and augmented reality in Oral \& Maxillofacial Surgery. BMC Oral Health 2019;19:238. https://doi.org/10.1186/s12903019-0937-8.

[4] von Sternberg N, Bartsch MS, Petersik A, Wiltfang J, Sibbersen W, Grindel T, et al. Learning by doing virtually. Int J Oral Maxillofac Surg 2007;36:386-90. https://doi.org/10.1016/j.ijom.2006.12.016.

[5] Bosc R, Fitoussi A, Hersant B, Dao T-H, Meningaud J-P. Intraoperative augmented reality with heads-up displays in maxillofacial surgery: a systematic review of the literature and a classification of relevant technologies. Int J Oral Maxillofac Surg 2019;48:132-9. https://doi.org/10.1016/j.ijom.2018.09.010.

[6] Soltanimehr E, Bahrampour E, Imani MM, Rahimi F, Almasi B, Moattari M. Effect of virtual versus traditional education on theoretical knowledge and reporting skills of dental students in radiographic interpretation of bony lesions of the jaw. BMC Med Educ 2019;19:233. https://doi.org/10.1186/s12909-019-1649-0.

[7] Durham M, Engel B, Ferrill T, Halford J, Singh TP, Gladwell M. Digitally Augmented Learning in Implant Dentistry. Oral Maxillofac Surg Clin N Am 2019;31:387-98. https://doi.org/10.1016/j.coms.2019.03.003.

[8] Jean-Baptiste Masson - Maxime Dahan $\dagger$ - (EN) Fabien Reyal - (EN) Bassam Hajj mohamed el beheiry - DIVA - Data Integration and Visualisation in Augmented and Virtual Environments | Research - Institut Pasteur n.d. https://research.pasteur.fr/fr/project/data-integration-and-visualisation-in-augmentedand-virtual-environments/ (accessed February 16, 2020).

[9] El Beheiry M, Godard C, Caporal C, Marcon V, Ostertag Ć, Sliti O, et al. DIVA: Natural Navigation inside 3D Images Using Virtual Reality. J Mol Biol 2020. https://doi.org/10.1016/j.jmb.2020.05.026.

[10] Klingenberg CP. MorphoJ: an integrated software package for geometric morphometrics. Mol Ecol Resour 2011;11:353-7. https://doi.org/10.1111/j.17550998.2010.02924.x.

[11] Ten Berge JMF. J.C. Gower and G.B. Dijksterhuis.Procrustes problems. New York: Oxford University Press. Psychometrika 2005;70:799-801. https://doi.org/10.1007/s11336-005-1390-y.

[12] McLachlan JC, Patten D. Anatomy teaching: ghosts of the past, present and future. Med Educ 2006;40:243-53. https://doi.org/10.1111/j.1365-2929.2006.02401.x.

[13] Triepels CPR, Smeets CFA, Notten KJB, Kruitwagen RFPM, Futterer JJ, Vergeldt TFM, et al. Does three-dimensional anatomy improve student understanding? Clin Anat 2020;33:25-33. https://doi.org/10.1002/ca.23405.

[14] Mascarenhas W, Richmond D, Chiasson G. CTRead-A Revolutionary Approach to Training Residents in Computed Tomography Facial Bone Interpretation. J Oral Maxillofac Surg 2019;77:1841-6. https://doi.org/10.1016/j.joms.2019.04.016.

[15] Alsabbagh AY, Watt-Smith S, Leeson R. Comparison of CT, 3D Reconstruction, and Virtual Reality in the Interpretation of Maxillofacial Fractures. $\mathrm{Br} \mathrm{J}$ Oral Maxillofac Surg 2019;57:e69. https://doi.org/10.1016/j.bjoms.2019.10.205. 
[16] Trelease RB. Anatomical informatics: Millennial perspectives on a newer frontier. Anat Rec 2002;269:224-35. https://doi.org/10.1002/ar.10177.

[17] Brouwers L, Pull Ter Gunne AF, de Jongh MA, Maal TJJ, Vreeken R, van der Heijden FHWM, et al. What is the value of $3 \mathrm{D}$ virtual reality in understanding acetabular fractures? Eur J Orthop Surg Traumatol Orthop Traumatol 2020;30:109-16. https://doi.org/10.1007/s00590-019-02537-w.

[18] Zhang J, Li D, Liu Q, He L, Huang Y, Li P. Virtual surgical system in reduction of maxillary fracture. 2015 IEEE Int. Conf. Digit. Signal Process. DSP, 2015, p. 1102-5. https://doi.org/10.1109/ICDSP.2015.7252050.

[19] Huang T-K, Yang C-H, Hsieh Y-H, Wang J-C, Hung C-C. Augmented reality (AR) and virtual reality (VR) applied in dentistry. Kaohsiung J Med Sci 2018;34:243-8. https://doi.org/10.1016/j.kjms.2018.01.009.

[20] Roessel J, Knoell M, Hofmann J, Buettner R. A systematic literature review of practical virtual and augmented reality solutions in surgery. COMPSAC 2020 Proc. Conf. 44th IEEE Comput. Softw. Appl. Conf. Madr. Spain, Madrid, Spain: COMPSAC 2020 Proceedings; 2020.

[21] Bartella AK, Kamal M, Scholl I, Schiffer S, Steegmann J, Ketelsen D, et al. Virtual reality in preoperative imaging in maxillofacial surgery: implementation of "the next level”? $\quad \mathrm{Br} \quad \mathrm{J} \quad$ Oral $\quad$ Maxillofac $\quad$ Surg 2019;57:644-8. https://doi.org/10.1016/j.bjoms.2019.02.014.

[22] Pulijala Y, Ma M, Ayoub A. VR Surgery: Interactive Virtual Reality Application for Training Oral and Maxillofacial Surgeons using Oculus Rift and Leap Motion. In: Ma M, Oikonomou A, editors. Serious Games Edutainment Appl. Vol. II, Cham: Springer International Publishing; 2017, p. 187-202. https://doi.org/10.1007/978-3-319-5164558.

[23] Estai M, Bunt S. Best teaching practices in anatomy education: A critical review. Ann Anat - Anat Anz 2016;208:151-7. https://doi.org/10.1016/j.aanat.2016.02.010.

[24] Pulijala Y, Ma M, Pears M, Peebles D, Ayoub A. Effectiveness of Immersive Virtual Reality in Surgical Training-A Randomized Control Trial. J Oral Maxillofac Surg Off J Am Assoc Oral Maxillofac Surg 2018;76:1065-72. https://doi.org/10.1016/j.joms.2017.10.002. 
Figure 1. 3D renderings provided by a freeware (RadiAnt, Medixant, Poznan, Poland) (A, B) and DIVA (C, D) for the per- and post-operative aspects of a Le Fort III fracture trauma case (case №3).

Figure 2. Exploring a pre-operative (A) and post-operative (B) Le Fort III trauma case (case 279 №3) using DIVA. 2D sections can be visualized on a box surrounding the 3D rendering, and 280 the used can interact with the 3D avatar using cutting tools, in order to better understand the 281 internal skull anatomy.

283 Figure 3. Low error values when positioning 3D landmarks using DIVA: all mean 3D errors 284 were lower than an arbitrary threshold of 1 millimeter. mm: millimeter; 3D: tridimensional; 285 ANS: anterior nasal spine; PNS: posterior nasal spine; Cusp_17: distal palatal cuspid of tooth 286 17; Cusp_27: distal palatal cuspid of tooth 17; Apex_C2: apex of the odontoid process of C2; 287 Apex_galli: apex of the crista galli process. 
288 Table legends

289

290 Table 1. Assessment of the use of VR in craniofacial trauma education by 50 undergraduate 7291 medical students from the University of Paris. 
Supplemental Digital Contents

2293

7295 on DIVA.

296

Supplemental Digital Content 2. Pre-operative virtual avatar (case №3) on DIVA with implementation of 2D sections and the cutting tool.

Supplemental Digital Content 3. Post-operative virtual avatar (case №3) on DIVA with implementation of 2D sections and the cutting tool.

303 Supplemental Digital Content 4. 3D distribution of anatomical landmarks placed by the 4 304 evaluators on a post-operative virtual avatar (case №3). 
2306 We acknowledge funding from Institut Pasteur, Institut Curie, Paris Sciences Lettres and the sponsorship of CRPCEN, Gilead-Sciences, and fondation EDF, the "programme 308 d'investissement d'avenir" supported by the "agence nationale de la recherche" ANR-19309 P3IA-0001 (PRAIRIE 3IA Institute), INCEPTION project (PIA/ANR- 16-CONV-0005, 310 OG)), and TRamWAy ANR-17-CE23-0016.

311 Special thanks to Kevin Bloch, Alexia Kany, Alice Prevost and Camille Rabot.

\section{Conflict of interest}

314 Mohamed El Beheiry and Jean-Baptiste Masson are cofounders, shareholders and scientific 315 advisors of Avatar Medical.

316 Jean-Baptiste Masson is one of the scientific advisors of the Robeaute startup. 

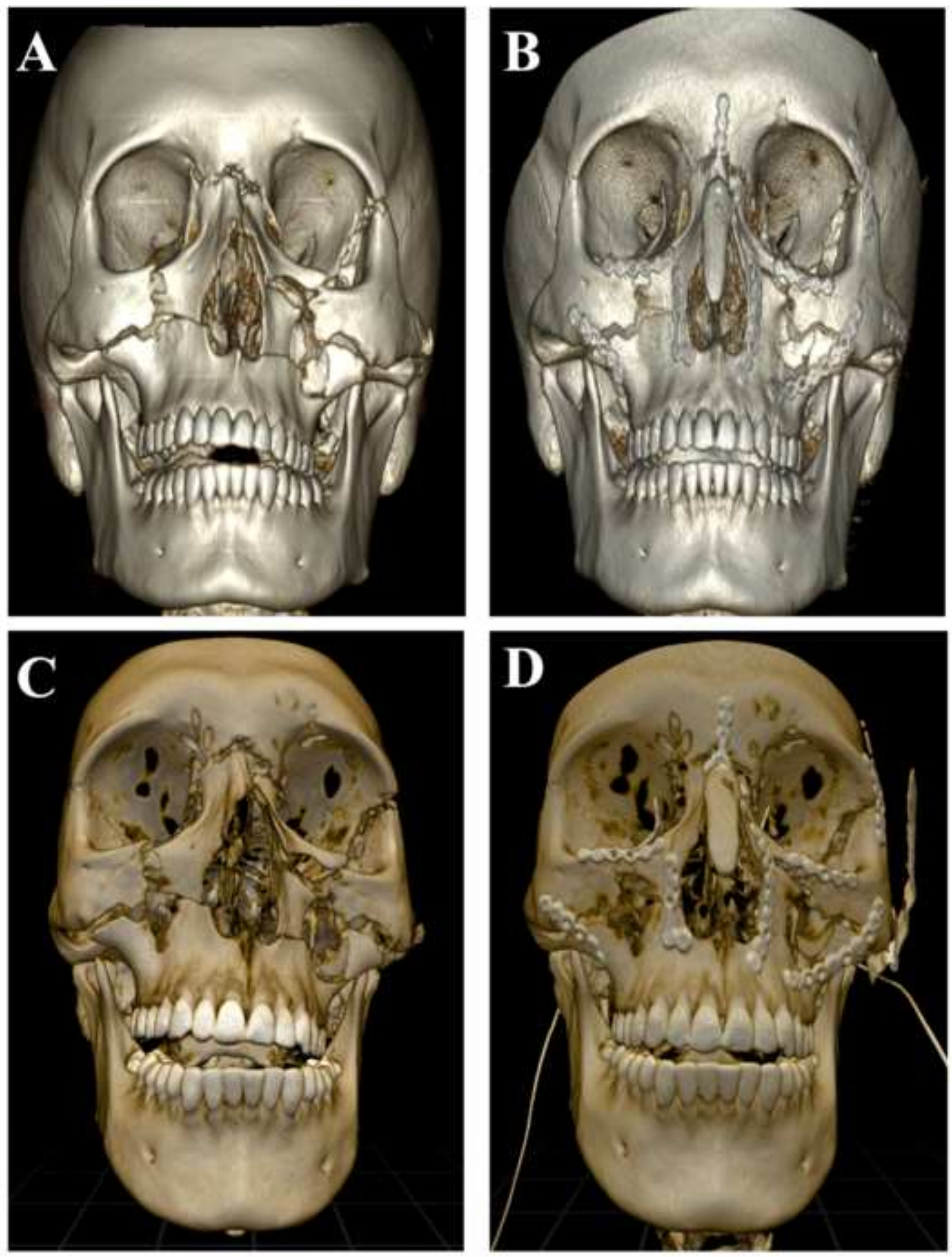

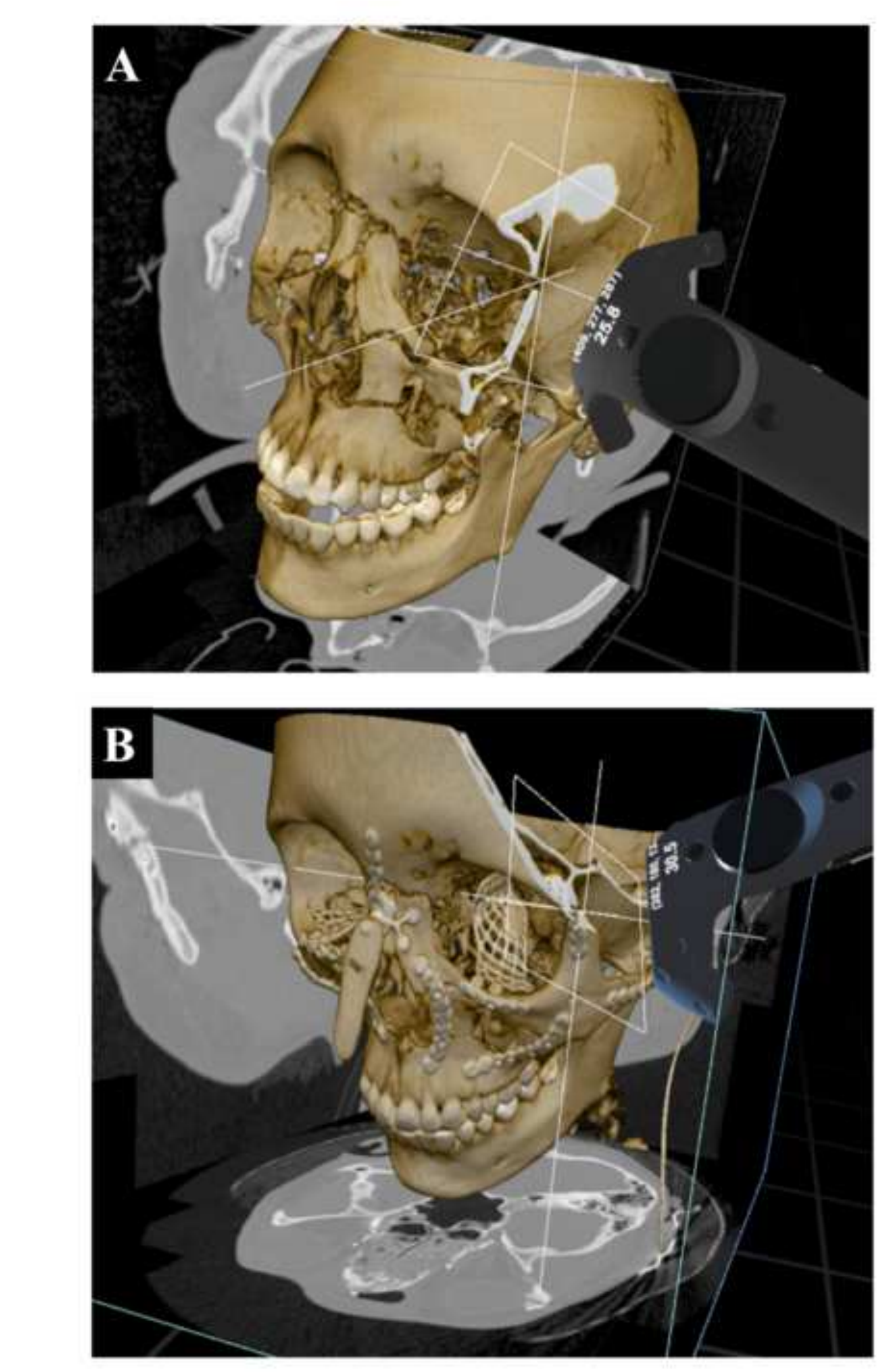

Figure 2

.
Click here to

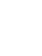




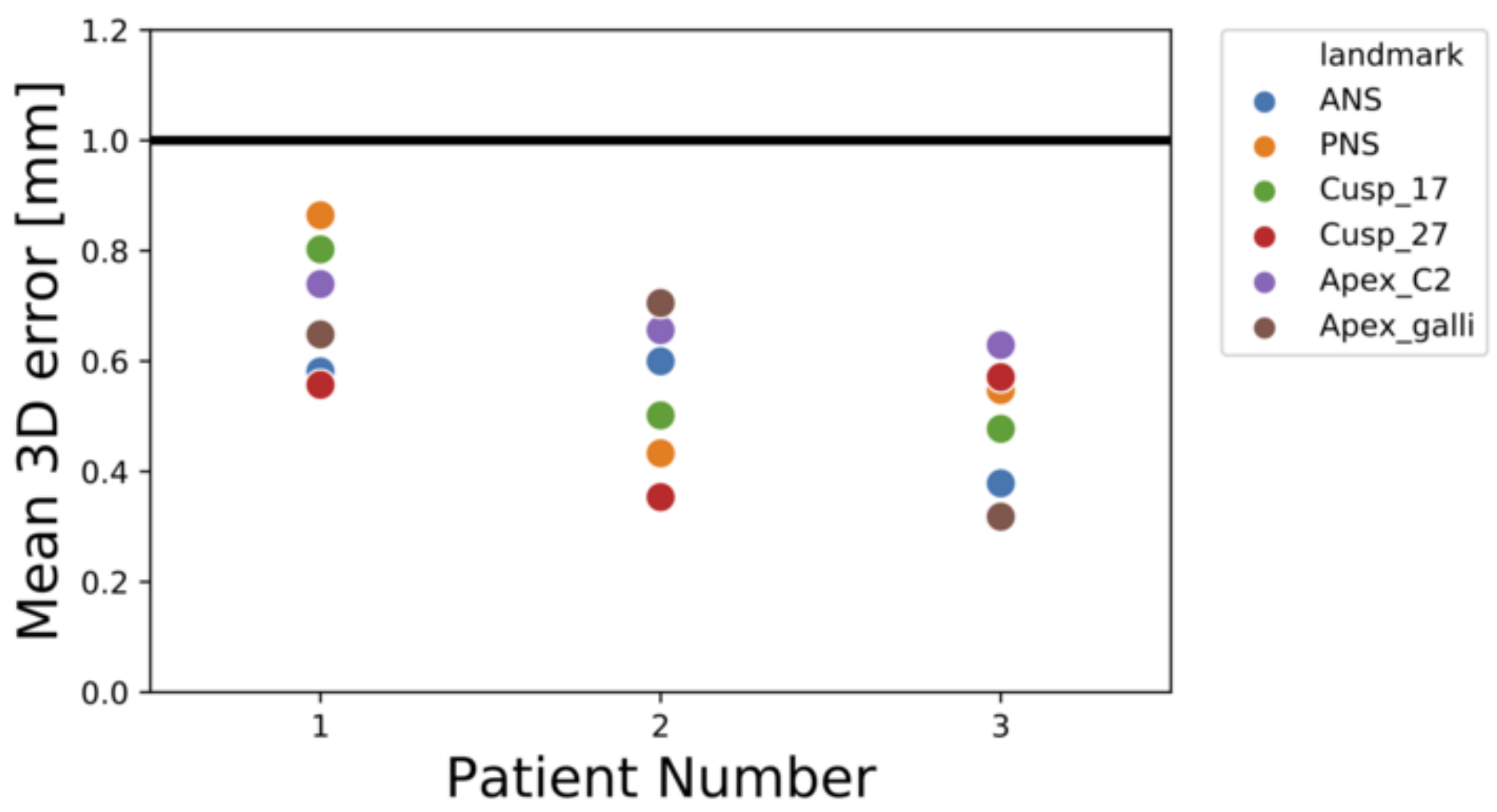




\begin{tabular}{|c|c|c|c|c|}
\hline Questions & Responses & \multicolumn{3}{|c|}{ Evaluation scale and more detailed student responses } \\
\hline $\begin{array}{l}\text { 1. Are you satisfied of DIVA when } \\
\text { exploring craniofacial trauma } \\
\text { cases? }\end{array}$ & $\begin{array}{l}\text { Yes } n=49 \\
\text { No } n=1\end{array}$ & $\begin{array}{l}\text { 5: very satisfied } \\
\text { 4: more than satisfied } \\
\text { 3: satisfied } \\
\text { 2: partly satisfied } \\
\text { 1: not at all satisfied }\end{array}$ & & $\begin{array}{l}5: n=27 \\
4: n=19 \\
3: n=4 \\
2: n=0 \\
1: n=0\end{array}$ \\
\hline $\begin{array}{l}\text { 2. Do you think that DIVA was } \\
\text { easy and intuitive to use? }\end{array}$ & $\begin{array}{l}\text { Yes } n=50 \\
\text { No } n=0\end{array}$ & $\begin{array}{l}\text { 5: very easy and intuitiv } \\
\text { 4: more than easy and in } \\
\text { 3: easy and intuitive } \\
\text { 2: partly intuitive } \\
\text { 1: not at all intuitive }\end{array}$ & & $\begin{array}{l}5: n=22 \\
4: n=22 \\
3: n=4 \\
2: n=2 \\
1: n=0\end{array}$ \\
\hline $\begin{array}{l}\text { 3. Have you experienced any } \\
\text { difficulties in tolerating the use } \\
\text { of DIVA? }\end{array}$ & $\begin{array}{l}\text { Yes } n=7 \\
\text { No } n=43\end{array}$ & \multicolumn{2}{|l|}{$\begin{array}{l}\square \text { visual fatigue } \\
\square \text { headaches } \\
\square \text { dizziness } \\
\square \text { nausea } \\
\square \text { other (precise) }\end{array}$} & $\begin{array}{l}\mathrm{n}=0 \\
\mathrm{n}=0 \\
\mathrm{n}=0 \\
\mathrm{n}=0 \\
\mathrm{n}=0\end{array}$ \\
\hline $\begin{array}{l}\text { 4. Does the use of DIVA allow you } \\
\text { to visualize some lesions not } \\
\text { suspected on usual 2D and 3D } \\
\text { renderings? }\end{array}$ & $\begin{array}{l}\text { Yes } n=41 \\
\text { No } n=9\end{array}$ & \multicolumn{3}{|c|}{$\begin{array}{l}\text { Fracture of the pterygoid processes were especially well } \\
\text { apprehended and visualized using DIVA. }\end{array}$} \\
\hline $\begin{array}{l}\text { 5. Does the use of DIVA allow you } \\
\text { to better visualize some lesions } \\
\text { seen on usual } 2 \mathrm{D} \text { and } 3 \mathrm{D} \\
\text { renderings? }\end{array}$ & $\begin{array}{l}\text { Yes } n=49 \\
\text { No } n=1\end{array}$ & \multicolumn{3}{|c|}{ Fractures lines were better visualized and understood } \\
\hline $\begin{array}{l}\text { 6. Do you think that DIVA was } \\
\text { beneficial to understand } \\
\text { maxillofacial trauma? }\end{array}$ & $\begin{array}{l}\text { Yes } n=50 \\
\text { No } n=0\end{array}$ & $\begin{array}{l}\text { 5: very profitable } \\
\text { 4: more than profitable } \\
\text { 3: profitable } \\
\text { 2: partly profitable } \\
\text { 1: not at all profitable }\end{array}$ & & $\begin{array}{l}=27 \\
=19 \\
=4 \\
=0 \\
=0\end{array}$ \\
\hline
\end{tabular}




\begin{tabular}{|c|c|c|c|}
\hline $\begin{array}{l}\text { 7. Do you VR is of interest for the } \\
\text { better understanding of } \\
\text { maxillofacial anatomy? Please } \\
\text { precise }\end{array}$ & $\begin{array}{l}\text { Yes } \mathrm{n}=48 \\
\text { No } \mathrm{n}=1\end{array}$ & \multicolumn{2}{|c|}{$\begin{array}{l}\text { It provides a better visualization of the maxillofacial } \\
\text { anatomy, which helps the comprehension of the } \\
\text { traumatology. }\end{array}$} \\
\hline $\begin{array}{l}\text { 8. Would you advise using DIVA } \\
\text { as a standard educational tool in } \\
\text { traumatology? }\end{array}$ & $\begin{array}{l}\text { Yes } \mathrm{n}=49 \\
\text { No } \mathrm{n}=1\end{array}$ & $\begin{array}{l}\text { 5: highly recommended } \\
\text { 4: more than recommended } \\
\text { 3: recommended } \\
\text { 2: partly recommended } \\
\text { 1: not at all recommended }\end{array}$ & $\begin{array}{l}5: n=25 \\
4: n=22 \\
3: n=2 \\
2: n=0 \\
1: n=1\end{array}$ \\
\hline
\end{tabular}

